\title{
ANÁLISE DOS LIVROS DIDÁTICOS DE QUÍMICA DO PNLD 2015 SOBRE A TEORIA ATÔMICA
}

\author{
Saniel Ferreira, Universidade Federal de Campina Grande (UFCG)
}

sanielferreira80@gmail.com

Fernanda Dias da Silva, Universidade Federal de Campina Grande (UFCG)

soufernandadias@gmail.com

Luciano Leal de Morais Sales, Universidade Federal de Campina Grande (UFCG)

luciano_sales@hotmail.com

PALAVRAS-CHAVE: Livro didático, Analogias, Modelo Atômico.

\section{INTRODUÇÃO}

O livro didático tem um papel relevante no processo ensino-aprendizagem de Química. Portanto deve ser escolhido pelos educadores de forma crítica, consciente e condizente com a realidade em que a escola esteja inserida. O contexto educacional contemporâneo exige, cada vez mais, um professor capaz de suscitar nos alunos experiências pedagógicas significativas, diversificadas e alinhadas com a sociedade na qual estão inseridos (Brasil, 1994). Dentro dessa perspectiva a escolha um livro didático, assume um papel relevante dentro do processo de ensino e aprendizagem. É necessário definir critérios de análise que irão nortear de forma adequada um recurso que se torna fundamental para a vida dos aluno. No ensino de Química, o uso de analogias constitui uma atividade bastante comum. Como reitera Carvalho \& Justi (2005), o ensino de ciências e, particularmente o da Química, envolve, muitas vezes, abstrações de difícil compreensão. Na tentativa de facilitar o aprendizado, professores e autores de materiais instrucionais desenvolvem modelos de ensino, isto é, representações produzidas com o objetivo específico de ajudar os estudantes a entenderem algum aspecto do conteúdo que se deseja ensinar. Dessa forma, os professores de Química, quando procuram explicar algum conceito ou modelo científico relativamente difícil, frequentemente recorrem ao uso de analogias. Normalmente, partem do pressuposto de que com o uso de uma determinada analogia, isto é, da apresentação de uma situação, de um objeto, de uma estrutura ou de um fenômeno semelhante ao que se pretende ensinar, aquele conceito terá se tornado mais claro, ou mais evidente e, portanto mais compreensível pelos estudantes, desde que esses tenham realizado as devidas correspondências (MÓL, 1999; FERRY, 2008). Como se pode 
perceber existe inúmeras análises, nas mais diversas perspectivas teóricas e preocupadas com diferentes aspectos específicos dos livros didáticos. A partir dela se têm condições de analisar os materiais didáticos agregando novos critérios àqueles que já vinham sendo adotados (APPLE, 1995)

Este trabalho tem como objetivo fazer uma caracterização das principais aspectos teóricos sobre o assunto de Teoria atômica presentes em livros didáticos de Química aprovados pelo Programa Nacional do Livro Didático (PNLD) de 2015, do Ministério da Educação (BRASIL, 2013) a fim de compreender potencialidades e limitações das relações analógicas estabelecidas pelos autores desses livros e da contextualização do conteúdo.

\section{METODOLOGIA}

Para a realização deste trabalho foram selecionados os livros: Ser protagonisda Química de Murilo Tissoni Antunes e Patricia A. dos Santos; Química cidadã de Wildson Luiz Pereira dos Santos e Gerson de Sousa Mol; Química de Eduardo Fleury Montiner e Andréa Machado e Química de Marta Reis, ambos do primeiro ano do ensino médio. Foram analisados os capitulos de Estrutura atômica dos mesmos através de critérios: (1) imagens presentes no livro didático; (2) linguagem e rigor científico; (3) evolução histórica do conteúdo; (4) contextualização do conteúdo; (5) relacionamento do conteúdo com o desenvolvimento tecnológico; (6) aspectos inerentes aos exercícios e problemas que são disponibilizados (Brasil, 1994).

\section{DESCRIÇÕES, RESULTADOS, INTERPRETAÇÕES...}

Tabela 1: Livros analisados

\begin{tabular}{|l|l|c|c|}
\hline \multicolumn{1}{|c|}{ LIVRO } & \multicolumn{1}{|c|}{ AUTORES } & EDITORA & DENOMINAÇÃO \\
\hline QUÍMICA & $\begin{array}{l}\text { Martha Reis Marques da } \\
\text { Fonseca }\end{array}$ & ÁTICA & LD1 \\
\hline SER PROTAGONISTA & Murilo Tissoni Antunes & SM & LD2 \\
\hline QUÍMICA CIDAD $\tilde{A}$ & $\begin{array}{l}\text { Eliane Nilvana Ferreira } \\
\text { de Castro/Gentil de Souza } \\
\text { Silva/Gerson de Souza } \\
\text { Mól/Roseli Takako }\end{array}$ & AJS & \\
\hline
\end{tabular}

Revista de Pesquisa Interdisciplinar, Cajazeiras, n. 2, suplementar, p. 216-55, set. de 2017. 


\begin{tabular}{|c|c|c|c|}
\hline & $\begin{array}{l}\text { Matsunaga/ } \\
\text { Salvia Barbosa Farias/ } \\
\text { Sandra Maria de Oliveira } \\
\text { Santos/Siland Meiry } \\
\text { França Dib/Wildson Luiz } \\
\text { Pereira dos Santos }\end{array}$ & & \\
\hline QUÍMICA & $\begin{array}{l}\text { Andréa Horta } \\
\text { Machado/Eduardo Fleury } \\
\text { Mortiner }\end{array}$ & SCIPIONE & LD4 \\
\hline
\end{tabular}

Fonte: Guia do livro didático 2015

Tabela 2 - Mostra a Análise dos Livros do PNLD 2015.

\begin{tabular}{|c|c|c|c|c|}
\hline CRITÉRIOS/LIVRO & $\overline{\text { LD1 }}$ & LD2 & LD3 & LD4 \\
\hline Imagens no livro* & $\begin{array}{c}\text { Número } \\
\text { intermediário de } \\
\text { ilustrações, mas } \\
\text { boa nitidez das } \\
\text { Ilustrações } \\
\text { imagens repedidas } \\
\text { diversas vezes } \\
\text { (14 imagens) }\end{array}$ & $\begin{array}{l}\text { Poucas ilustrações, mas } \\
\text { boa nitidez. } \\
\text { (05 imagens) }\end{array}$ & $\begin{array}{c}\text { Grande } \\
\text { quantidade de } \\
\text { imagens com alto } \\
\text { valor informativo } \\
\text { (67 imagens) }\end{array}$ & $\begin{array}{c}\text { Grande quantidade } \\
\text { de imagens com } \\
\text { alto valor } \\
\text { informativo } \\
\text { (80 imagens) }\end{array}$ \\
\hline $\begin{array}{l}\text { Linguagem e rigor } \\
\text { científico }\end{array}$ & $\begin{array}{c}\text { Linguagem bem } \\
\text { acessível sem } \\
\text { fugir da linguagem } \\
\text { científica } \\
\text { empregando } \\
\text { sempre que } \\
\text { necessária, } \\
\text { proporcionando } \\
\text { fácil } \\
\text { entendimento. }\end{array}$ & $\begin{array}{c}\text { Linguagem } \\
\text { estimulante, mas } \\
\text { mantendo a } \\
\text { cientificidade. }\end{array}$ & $\begin{array}{c}\text { Linguagem } \\
\text { estimulante, e } \\
\text { associada a fatos } \\
\text { do cotidiano. }\end{array}$ & $\begin{array}{l}\text { Linguagem pouco } \\
\text { sucinta, e quase } \\
\text { nenhum rigor } \\
\text { científico. }\end{array}$ \\
\hline $\begin{array}{l}\text { Evolução histórica do } \\
\text { conteúdo }\end{array}$ & $\begin{array}{c}\text { A evolução } \\
\text { histórica deixa } \\
\text { muito a deseja, já } \\
\text { que não há relatos } \\
\text { dos cientistas } \\
\text { responsáveis pelas } \\
\text { descobertas das }\end{array}$ & $\begin{array}{c}\text { Evolução dos } \\
\text { conteúdos históricos } \\
\text { em relação aos } \\
\text { conceitos do tema } \\
\text { bastante resumidos. }\end{array}$ & $\begin{array}{c}\text { Bom } \\
\text { desenvolvimento } \\
\text { histórico dos } \\
\text { conceitos sempre } \\
\text { os relacionando } \\
\text { aos cientistas } \\
\text { responsáveis por }\end{array}$ & $\begin{array}{c}\text { A evolução } \\
\text { histórica e bem } \\
\text { abordada, seguindo } \\
\text { bem seus } \\
\text { paramentos } \\
\text { evolutivos. }\end{array}$ \\
\hline
\end{tabular}

Revista de Pesquisa Interdisciplinar, Cajazeiras, n. 2, suplementar, p. 216-55, set. de 2017. 


\begin{tabular}{|c|c|c|c|c|}
\hline & teorias. & & eles. & \\
\hline Contextualização & $\begin{array}{c}\text { Possui muita } \\
\text { deficiência nesse } \\
\text { ponto. }\end{array}$ & $\begin{array}{c}\text { Conteúdo bem } \\
\text { contextualizado, porém } \\
\text { não há associação com } \\
\text { o cotidiano. }\end{array}$ & $\begin{array}{c}\text { Bastante } \\
\text { contextualizado e } \\
\text { relacionado com o } \\
\text { cotidiano dos } \\
\text { discentes. }\end{array}$ & $\begin{array}{c}\text { Boa } \\
\text { contextualização, } \\
\text { mais deixa a deseja } \\
\text { na abordagem do } \\
\text { cotidiano. }\end{array}$ \\
\hline $\begin{array}{c}\text { Relacionamento com o } \\
\text { desenvolvimento } \\
\text { tecnológico }\end{array}$ & Não possui & $\begin{array}{l}\text { Não Demonstra } \\
\text { grandes avanços } \\
\text { tecnológicos } \\
\text { relacionados com a } \\
\text { aplicação de conceitos } \\
\text { estudados. }\end{array}$ & $\begin{array}{c}\text { Manifesta } \\
\text { afinidade com } \\
\text { recentes } \\
\text { descobertas } \\
\text { tecnológicas e } \\
\text { pesquisas acerca } \\
\text { do conteúdo. }\end{array}$ & $\begin{array}{l}\text { Perfeita abordagem } \\
\text { tecnológica } \\
\text { demonstrando a } \\
\text { influência da } \\
\text { ciência na } \\
\text { sociedade. }\end{array}$ \\
\hline $\begin{array}{c}\text { Aspectos inerentes aos } \\
\text { exercícios }\end{array}$ & $\begin{array}{c}\text { Exercícios } \\
\text { contextualizados } \\
\text { que remetem a } \\
\text { conteúdos } \\
\text { anteriormente } \\
\text { estudados. }\end{array}$ & $\begin{array}{l}\text { Elevação no grau de } \\
\text { dificuldade e } \\
\text { contextualização dos } \\
\text { exercícios a cada } \\
\text { questão. }\end{array}$ & $\begin{array}{l}\text { Demonstra clara } \\
\text { deficiência } \\
\text { oferecendo muitas } \\
\text { questões, porém } \\
\text { sem } \\
\text { problematização } \\
\text { alguma. }\end{array}$ & $\begin{array}{c}\text { Exercício bem } \\
\text { contextualizado } \\
\text { visando prepara os } \\
\text { alunos para } \\
\text { vestibulares e } \\
\text { Enem. }\end{array}$ \\
\hline
\end{tabular}

Fonte: Próprio autor

Segundo os dados da Tabela 2, os resultados obtidos, foram elaborados através da leitura dos capitulos sobre modelo atômico dos respectivos livros, observando eventuais dificuldades que alunos de ensino médio, possam vir a encontra no decorrer da leitura, caso estejam sem o auxilio de um docente, ou seja, qual seriam suas limitações ao tentarem aprender lendo o determinado conteúdo.

Com base nos dado coletado no primeiro critério da Tabela 2, pode -se concluir os números de imagens por livro e deduzi que livros de baixa ilustrações comprometem o aprendizado. relação às imagens em um livro didático, pode-se verificar que a amostra LD1 tem Número intermediário de ilustrações com cerca de 14 ilustrações no que representa um número sucinto de imagens, pois compreende-se que as imagens trazem uma boa compreensão para o leitor do assunto. Neste aspecto, nota-se que a amostra LD2 tem a menor 
quantidade de ilustrações da lista PNLD 2015, dificultando demais o entendimento do assunto pelos discentes. A dedução da amostra LD3 com 67 imagens e a amostra LD4 com cerca de 80 imagens demonstraram através da mesma uma alto valor informativo, levando o leitor através de ilustrações compreender de forma mais simples teorias complexas.

De acordo com a Tabela 2, verifica-se que a linguagem cientifica deve ser aplicada com boa contextualização de situações contidas no cotidiano dos discentes, ao analisar a linguagem cientifica dos capítulos de modelo atômico pode-se perceber que a coleção LD1 destacou-se por possuir uma linguagem bem acessível sem fugir da linguagem científica empregando-a sempre que necessária, proporcionando fácil entendimento. Seguida do livro LD3 que apresentou uma linguagem bastante associada a fatos do cotidiano. O livro LD2 apresentou linguagem estimulante, mas mantendo a cientificidade. A coleção LD4 propôs uma abordagem pouco sucinta, e com quase nenhum rigor científico.

Ao analisar os dados mostrados no Quadro 2, modelo atômico, deve partir desde os conceitos iniciais como o surgimento do primeiro modelo atômico sua evolução durante os anos ate os dias atuais e os cientistas responsáveis por tais descobertas. Neste contexto buscase a necessidade de um ensino que não transmita apenas conteúdos e fórmulas, mas sim busque um ensino compreenda a história da Química. Assim, analisando a evolução histórica contida nesses livros pode -se compreender que dois deles trazem um desenvolvimento histórico favorável a construção do conhecimento do conteúdo, sendo o LD3 mais completo em relação à evolução histórica anteriormente citada e a coleção LD4. A coleção LD2 e o livro LD1 não apresenta essa evolução histórica, tampouco uma definição de conceitos para ser trabalhado o conteúdo, fragilizando o processo de aprendizagem dos discentes.

A contextualização de alguns conteúdos quando não transmitidas com clareza, chegam a se tornar conteúdos de difícil compreensão para alguns leitores como é o caso do modelo atômico. Em relação a contextualização nas quatro obras analisadas, apenas a obra LD3 relaciona fatos do cotidiano com o contexto estudado pelos alunos buscando melhorar a aprendizagem significativa. As demais obras não contemplam nenhuma relação com o cotidiano dos discentes, sendo, portanto muito deficiente nesta questão.

O conteúdo de modelo atômico esta presente em várias áreas da tecnologia, pesquisas, aplicações na indústria, na medicina entre outras. Nesse caso o Quadro 2 traz o 
relacionamento do assunto com o avanço da tecnologia.Com relação a abordagem metodológica de apresentação dos conteúdos, nota-se que o livro LD3 e a coleção LD4 analisados trazem uma sequência de conceitos que facilitam a compreensão do conteúdo, Manifesta afinidade com recentes descobertas tecnológicas e pesquisas acerca do conteúdo e Perfeita abordagem tecnológica demonstrando a influência da ciência na sociedade. A coleção LD2 possui uma pequena deficiência na apresentação de sua abordagem metodológica de seus conceitos, o que pode dificultar na compreensão do mesmo. A coleção LD1 não possui nenhuma organização de conceitos e ideias dificultando o processo de aprendizagem.

Ao serem contemplados os exercícios apresentados em cada livro didático assim como afirma Otesbelgue (2013), o qual prediz que os exercícios têm papel fundamental na formação do aluno, pois pode forçar o mesmo a contextualizar mais, levando os discentes a pesquisar sobre o assunto estudado. Assim, considera-se que as obras LD1, LD2 e LD4 trazem questões adequadas às necessidades dos alunos, Exercícios contextualizados que remetem a conteúdos anteriormente estudados, levando o aluno a questionar, interpretar, avaliar e problematizar até chegar a resposta esperada, visando prepara- lós para vestibulares e Enem. Na obra LD3, há uma grande quantidade dos exercícios, porém sua maioria é dada de uma forma bem direta, demonstrando clara deficiência em sua problematização.

\section{CONSIDERAÇÕES FINAIS}

A partir da análise dos quatros livros propostos pela PNLD de 2015, podemos concluir que o livro LD3, teve um melhor desempenho nos critérios propostos pela análise. Os demais livros, possuíam pontos negativos que vieram assim, não considerá-los adequados ao nível de cobranças exigidos pelos vestibulares e Enem ou ate mesmo ao nível de compreensão de estudantes de ensino médio quando comparados aos demais. Podemos ressaltar que, dentre os quatro livros propostos pela PNLD de 2015, o livro LD2, teve o pior resultado nos cincos critérios abordados para a análise dos livros. Podemos observa que todos os exemplares não abordaram o tema modelo atômico no início do livro, como todos os alunos de Química esperam, já que, o determinado assunto, pode ser considerado o início da Química no mundo.

Por fim, consideramos que os autores dos livros didáticos, busquem ter uma visão mais criteriosa na criação de seus livros, visando uma melhor compreensão de seus leitores. 


\section{REFERÊNCIAS}

APPLE, Michael W. Trabalho Docente e Textos: Economia Política das Relações de Classe e Gênero em Educação; Artes Médicas, Porto Alegre, 1995.

BRASIL. MEC. Definição de critérios para avaliação dos livros didáticos. Brasília, 1994.

BRASIL, Ministério da Educação. Edital de convocação 01/2013 - CGPLI. Edital de convocação para o processo de inscrição e avaliação de obras didáticas para o Programa Nacional do Livro Didático - PNLD 2015, 2013.

CARVALHO, N.; JUSTI, R. Papel da Analogia do "mar de elétrons" na compreensão do modelo de ligação metálica. Enseñanza de las Ciências. Numero extra. VII Congresso, 2005.

CORDEIRO, Marinês D.; PEDUZZI, Luiz O.Q. Consequências das de contextualizações em um livro didático: uma análise do tema radioatividade. Revista Brasileira de Ensino de Física, v. 35, n. 3, p. 3602, 2013.

FERRY, A. S. Analogias e Contra-analogias: uma estratégia auxiliar para o ensino de modelos atômicos. Belo Horizonte: Centro Federal de Educação Tecnológica de Minas Gerais, [Dissertação de Mestrado], 2008.

LUIZ, W.P.S; SOUZA, G.M. Química Cidadã: Vol.1. 2.ed, São Paulo: Editora AJS, 2013.

MÓL, G. S. O uso de analogias no ensino de Química. Brasília: Universidade de Brasília Instituto de Química, [Tese de Doutorado], 1999.

MORTMER, E.F; MACHADO, A.H; Química: Vol.1. 2.ed, São Paulo: editora scipione, 2013.

REIS, MARTHA. Química: Vol.1. 1.ed, São Paulo: editora ática, 2013. 
SILVA. Thiago P.; Souza. Monica M.; Barros. Ana Patrícia M.; Barbosa. Daniela B. Análise De Livros Didáticos De Química Do PNLEM 2012. Universidade Estadual da ParaíbaUEPB, (sem ano)

TISSONI, M. A; SANTOS, P. A. Ser Protagonista: Química: Revisão do ensino médio. Vol. Único. 1.ed, São Paulo: Edições SM, 2014.

TIMOTEO; W. S. Trabalho de Conclusão de Curso: A RADIOATIVIDADE NO ENSINO MÉDIO: análise de livros didáticos de Química do PNLD 2015. Universidade Federal de Campina Grande, 2016. 